\title{
Folga organizacional versus desempenho financeiro Um estudo nas empresas da BM \& FBovespa
}

Ilse Maria Bueren

Universidade Federal do Paraná

ilse.beuren@gmail.com

Loriberto Starosky Filho Universidade Regional de

Blumenau

Istarosky@furb.br

\section{Nayane Thais Krespi}

Universidade Regional de

Blumenau

nayanethais@ibest.com.br

\section{Resumo}

Este estudo objetiva identificar a relação de diferentes formas de folga organizacional com o desempenho financeiro das empresas listadas na BM\&FBovespa, levando em consideração fatores antecedentes destacados por Sharfman Wolf, Chase e Tansik (1988). Dados de 273 empresas foram coletados na Economática ${ }^{\circledR}$, além de consultas nas demonstrações contábeis dos anos de 2006 a 2010. Seguindo os procedimentos adotados no estudo replicado de George (2005), calculou-se a matriz de correlação e a estatística descritiva das variáveis. Analisou-se também graficamente o comportamento dos critérios de alta e baixa folga em relação ao desempenho financeiro das empresas e efetuou-se a análise de dados em painel, utilizando o modelo de efeitos fixos. Os resultados mostram que os modelos utilizados naquele estudo não foram altamente explicativos nesta pesquisa. Todavia, obteve-se relação significante entre o desempenho financeiro e o critério de baixa folga. Ainda que de modo preliminar, é possível concluir que o aumento da baixa folga implica em aumento do desempenho financeiro, mas no longo prazo esse desempenho apresenta uma tendência de decréscimo. Como a folga organizacional foi constituída de forma diferente nas empresas pesquisadas por George (2005) e as deste estudo, amplia-se o campo de investigação para explicações sobre as divergências.

Palavras-chave: folga organizacional, desempenho financeiro, avaliação de desempenho. 


\title{
Organizational slack versus financial performance. A study of companies on BM\&FBovespa
}

\begin{abstract}
This goal of this study is to identify the relationship between different forms of organizational slack with the financial performance of companies listed on Bovespa, taking into consideration previous factors highlighted by Sharfman, Wolf, Chase and Tansik (1988). Data of 273 companies were collected from Economática ${ }^{\circledR}$, besides consultations in the financial statements of the years from 2006 to 2010. Following the procedures adopted in the replicated study of George (2005), the correlation matrix and descriptive statistics of the variables were calculated. It was also analyzed graphically the behavior of the criteria of high and low slack against the financial performance of companies and the analysis of panel data was done, using the fixed effects model. The results show that the models used in that study were not highly explanatory in this research. However, a significant relationship between financial performance and the criterion of low slack was obtained. Even in a preliminary way, it is possible to conclude that the increase of low slack results in the increase of financial performance, but in the long run this performance shows a decreasing trend. As the organizational slack was constituted differently in the companies surveyed by George (2005) and in the ones in this study, the field of investigation for explanations of the differences is enlarged.
\end{abstract}

Keywords: organizational slack, financial performance, performance evaluation.

\section{Holgura organizacional versus desempeño financiero. Un estudio en las em- presas del BM\&FBovespa}

\section{Resumen}

Este estudio tiene como objetivo identificar la relación entre las diferentes formas de holgura organizacional con el desempeño financiero de las empresas que cotizan en la BM\&FBovespa, teniendo en cuenta los factores de fondo señalados por Sharfman Wolf, Chase y Tansik (1988). Se recogieron datos de 273 empresas en Economática ${ }^{\circledR}$, así como se consultaron los estados financieros de 2006 a 2010. Siguiendo los procedimientos adoptados en el estudio replicado de George (2005), se calculó la matriz de correlación y estadísticos descriptivos de las variables. También se analizó gráficamente el comportamiento de los criterios de reacción alta y baja frente al desempeño financiero de las empresas y se realizó el análisis de datos de panel utilizando el modelo de efectos fijos. Los resultados muestran que los modelos utilizados en este estudio no fueron altamente explicativos en esta búsqueda. Sin embargo, se obtuvo una relación significativa entre el desempeño financiero y el criterio de baja holgura. Aunque preliminar, se concluye que el aumento de la 
baja holgura implica un mayor desempeño financiero, pero a la larga este comportamiento muestra una tendencia decreciente. Como la holgura organizacional se constituyó de manera diferente en las empresas encuestadas por George (2005), este estudio amplía el campo de la investigación para la explicación de las diferencias.

Palabras clave: holgura organizacional, desempeño financiero, evaluación del desempeño.

\section{Introdução}

As organizações deparam-se constantemente com o desafio de melhorar seu desempenho e, consequentemente, assegurar seu crescimento. Esta dicotomia tem uma estreita relação com a utilização dos recursos da organização e com a decisão de alocar recursos em ativos que proporcionem maior liquidez e rentabilidade.

Os recursos influenciam as aspirações dos gestores. Eles funcionam como estimulantes, proporcionando ao gestor experimentar mais ou menos riscos, dependendo das decisões estratégicas tomadas. Os recursos também são"utilizados para construir as capacidades que tornam as empresas competitivas" (George, 2005: 2), assegurando aos gestores e acionistas a realização de seus objetivos pessoais.

Os recursos podem também servir de colchão, um porto seguro, quando o mercado encontra-se retraído e em queda, conforme Bourgeois (1981). A folga organizacional, ou o excesso de recursos e seu impacto sobre o desempenho, tem motivado vários estudos à luz de teorias organizacionais e da prática de gestão, como os de Sharfmann, Wolf, Chase e Tansik (1988), Bromiley (1991), Moses (1992), Nohria e Gulati (1996, 1997), Kren (2003).

Embora o excesso não seja bem visto e frequentemente relacionado a algo prejudicial, ele tem sido utilizado para a consecução dos objetivos da organização, que consistem em crescer com desempenho positivo crescente, inovando e desenvolvendo novas estratégias. George (2005) afirma que pesquisadores têm oferecido explicações estratégicas e comportamentais sobre os fatores que induzem ou impelem as organizações a competir e obter sucesso no cenário competitivo. Neste contexto competitivo, os recursos que a organização dispõe exercem papel fundamental para o êxito de seus objetivos.

Os recursos, segundo George (2005), podem variar em tipo e forma. Os tipos mais comuns são recursos de capital, social ou financeiro. E quanto à forma, subdivi- 
dem-se em discricionários e não discricionários. A folga de recursos pode contribuir na tomada de decisões em relação aos riscos, para investimentos em inovação e avaliação de desempenho (George, 2005). Esta última é focalizada neste estudo, relacionando variáveis financeiras com variáveis não-financeiras, como tempo de atividade e quantidade de plantas da organização.

Lima (2008) destaca que frequentemente as organizações sacrificam a rentabilidade em nome do crescimento. $\mathrm{O}$ autor destaca que o desempenho organizacional é multidimensional, ou seja, envolve desempenho nas dimensões financeira, operacional e junto aos stakeholders. Explica ainda que "o desempenho efetivo em uma dimensão pode representar um custo quanto ao desempenho efetivo em outra dimensão" (Lima, 2008: 39).

Para medir o desempenho é necessária a utilização de sistemas de avaliação, que proporcionam informações aos gestores para tomada de decisões. Na literatura encontram-se sistemas de avaliação com enfoque no desempenho financeiro, tendo enfoque em medidas contábeis, operacionais, baseadas no mercado e medidas de sobrevivência (Lima, 2008). Este estudo pretende ir além da dimensão financeira, relacionando a folga organizacional com o desempenho, abordando as outras dimensões destacadas por Lima (2008).

A relação entre o desempenho e a folga organizacional tem sido tema de pesquisa de vários pesquisadores. Alguns deles, como Bromiley (1991), Wiseman e Bromiley (1996), Tan e Peng (2003), trabalharam com abordagens relacionadas ao desempenho financeiro. Outros autores, como Singh (1986), Bromiley (1991), Nohria e Gulati (1996), relacionaram desempenho e folga organizacional com e inovação tecnológica.

George (2005) ressalta o fato de que os estudos em empresas de capital aberto e argumentos comportamentais sugerem que a folga influencia positivamente o desempenho econômico-financeiro. Mas destaca o fato de que existem outros argumentos e limitações necessários para explicar a relação entre folga organizacional e desempenho empresarial. Em contraponto, George (2005: 3) observa que poucos estudos ocorrem em relação às empresas de capital fechado, deixando, segundo seu entendimento, "uma lacuna no entendimento de como a folga financeira pode influenciar o desempenho nestas empresas". 
Os resultados do estudo de George (2005), que objetivou distinguir as várias formas de articular a folga organizacional com o desempenho financeiro de empresas americanas de capital fechado, serviram de base para este estudo. Os resultados apontam que há relação entre folga organizacional e desempenho das organizações, e que os fatores idade e complexidade da organização contribuem para corroborar esta premissa.

Neste sentido elaborou-se a seguinte questão de pesquisa: Qual a relação de diferentes formas de folga organizacional com o desempenho financeiro das empresas listadas na BM\&FBovespa? Assim, este artigo objetiva identificar a relação das diferentes formas de folga organizacional no desempenho financeiro das organizações, levando em consideração fatores antecedentes destacados por Sharfman, Wolf, Chase e Tansik (1988). Para análise dos dados, coletados por meio de pesquisa documental, replicaram-se os procedimentos adotados no estudo de George (2005).

O estudo justifica-se por existirem poucas pesquisas nacionais em relação a esse tema. Na literatura internacional encontram-se pesquisas interessantes acerca da folga organizacional. Entretanto, do ponto de vista nacional o tema ainda permite avançar em pesquisas buscando a consolidação e, consequentemente, preencher lacunas existentes. Neste sentido, optou-se por realizar este estudo, verificando o comportamento da folga organizacional e o desempenho financeiro de empresas brasileiras de capital aberto, com vistas a ampliar a literatura nacional acerca do tema e cotejar os resultados da pesquisa.

\section{Folga organizacional}

A origem do termo folga organizacional, conforme Lima (2008: 45), "pode ser creditada à inducement-contribution ratio de Barnard em 1938". Cyert e March (1963) conceberam a folga organizacional como uma oferta de recursos não autorizados. A partir das proposições destes autores, uma vasta literatura foi desenvolvida em defesa ou contrária a criação da folga nas organizações, além de diferentes abordagens e tentativas de mensuração.

Dimick e Murray (1978) entendem que a folga organizacional, na sua essência, corresponde aos recursos que podem ser utilizados de maneira discricionária. Para Bourgeois (1981), a folga permite que recursos reais ou potenciais de uma organização se adaptem com sucesso às pressões internas, bem como para iniciar 
mudanças na estratégia. Para o autor, através deste duplo papel interno e externo, a folga influencia o desempenho da organização.

$\mathrm{O}$ "tema folga organizacional pode ser visto sob um prisma que ao mesmo tempo em que promove um incentivo para oportunidades de inovação, também é uma forma de desperdício e gastos que afetam negativamente os resultados e o desempenho da empresa" (Facó, 2009: 67). A folga é usada para estabilizar as atividades da empresa, absorvendo o excesso de recursos durante períodos de crescimento e possibilitando a manutenção dos seus compromissos durante períodos de crise (George, 2005).

A folga organizacional tem sido objeto de vários estudos, como Bourgeois (1981), Sharfman, Wolf, Chase e Tansik (1988), Bromiley (1991), Moses (1992), Nohria e Gulati (1996, 1997), Greenley e Oktembil (1998), Lawson (2001), Kren (2003), Tan e Peng (2003), sob os mais variados enfoques. Ela é normalmente caracterizada pelo excesso de recursos necessários ao funcionamento das organizações (Sharfman, Wolf, Chase, \& Tansik, 1988).

Segundo Lima (2008: 45), "embora a folga organizacional tenha sido reconhecida por diversos pesquisadores, ainda não há uma definição consensual do que ela efetivamente represente". Isto decorre, primeiro, porque as informações necessárias para a realização do cálculo da folga não estão normatizadas; e, segundo, pelo fato de pretender captar a capacidade de reagir a mudanças ambientais que é uma condição em constante alteração.

A organização apresenta folga quando possui excesso de recursos necessários ao seu funcionamento, considerando um contexto normal, de acordo com Bromiley (1991). A folga ocorre quando os recursos são em montante superior ao que seria suficiente para a empresa reagir frente a mudanças no ambiente em que opera. Para Nohria e Gulati (1997), a folga tem relação com o excesso de recursos, além do mínimo necessário. Os autores incluem na folga organizacional recursos financeiros, recursos com pessoal, despesas com capital desnecessárias, oportunidades inexploradas e capacidade não utilizada.

George (2005) cita que apenas três estudos conceituais têm articulado uma justificativa para a existência de formas de folga: Bourgeois (1981), Bourgeois e Singh (1983) e Sharfman, Wolf, Chase e Tansik (1988). Estes estudos apresentam clas- 
sificações de folga com base em critérios de distribuição de recursos, dividindo-os em folga absorvida e não absorvida. A folga absorvida, ou recuperável, é representada por recursos já absorvidos pela empresa, e que podem ser recuperados com aumento de eficiência. A característica desta folga é o baixo critério discricionário, ou seja, o gestor tem pouca flexibilidade na aplicação de ações estratégicas. A folga não absorvida, também referenciada como folga disponível, representa os recursos disponíveis e não empregados em ações estratégicas, e tem característica de alto critério discricionário.

Segundo Sharfman, Wolf, Chase e Tansik (1988), para que os recursos sejam identificados como folga, eles precisam ser visíveis para os gestores e empregáveis no futuro. Sender (2004: 20) reforça a ideia, explicando que "excessos de recursos, como perdas ou o resultado de estoque com problemas podem se tornar folga em algumas ocasiões, mas não podem ser considerados como tal até que sua finalidade seja alterada".

Estes conceitos são empregados no decorrer deste estudo, e tem como finalidade testar se os critérios discricionários de alta e baixa folga influenciam no desempenho das organizações. Adiante, verificam-se alguns conceitos importantes relacionados à folga organizacional e que foram sintetizados por Santos (2010), constantes no quadro 1 .

\section{Quadro 1}

\section{Conceitos de folga organizacional}

\begin{tabular}{c|l}
\hline Autores & \multicolumn{1}{c}{ Conceito de folga organizacional } \\
\hline Bourgeois (1981) & $\begin{array}{l}\text { É aquele 'colchão' de recursos efetivos ou potenciais que } \\
\text { permitem a uma organização adaptar-se com sucesso às pressões } \\
\text { internas de ajustes ou às pressões externas por mudaças em } \\
\text { políticas, assim como iniciar mudanças em estratégias com } \\
\text { respeito ao ambiente externo. }\end{array}$ \\
\hline $\begin{array}{c}\text { Sharfman, Wolf, Chase e } \\
\text { Tansik (1988) }\end{array}$ & $\begin{array}{l}\text { Compreende recursos em excesso, potencialmente recuperáveis } \\
\text { que uma organização necessita para manter suas operações } \\
\text { normais. }\end{array}$ \\
\hline Bromiley (1991) & $\begin{array}{l}\text { É o excesso de recursos que uma empresa pode utilizar para } \\
\text { aliviar as diferenças entre mudanças no ambiente em que opera } \\
\text { e a necessidade de respostas organizacionais. }\end{array}$ \\
\hline $\begin{array}{l}\text { Moses } \\
(1992)\end{array}$ & $\begin{array}{l}\text { As definições preponderantes de folga organizacional a } \\
\text { consideram como sendo constituída de recursos possuídos pela } \\
\text { empresa em montante superior às suas necessidades para fazer } \\
\text { frente às suas atividades. }\end{array}$ \\
\hline
\end{tabular}




\begin{tabular}{c|l}
\hline $\begin{array}{c}\text { Nohria e Gulati (1996, } \\
\text { 1997) }\end{array}$ & $\begin{array}{l}\text { É o conjunto de recursos em uma organização que está além do } \\
\text { mínimo necessário para produzir um dado nível de produção. }\end{array}$ \\
\hline $\begin{array}{c}\text { Greenley e Oktemgil } \\
\text { (1998) }\end{array}$ & $\begin{array}{l}\text { Recursos que não foram empregados de forma ótima, } \\
\text { mas que permitem à empresa adaptar-se às mudanças no } \\
\text { ambiente, fornecendo os meios para alcançar flexibilidade no } \\
\text { desenvolvimento de opções estratégicas de forma a buscar } \\
\text { oportunidades. O resultado de gerar e investir recursos de folga } \\
\text { para atingir flexibilidade deve ser melhorar o desempenho. } \\
\text { Recursos de folga são mantidos como um seguro contra perdas } \\
\text { futuras potenciais. }\end{array}$ \\
\hline $\begin{array}{c}\text { Lawson } \\
\text { (2001) }\end{array}$ & $\begin{array}{l}\text { Tempo disponível, ou dinheiro para comprar este tempo, que } \\
\text { não esteja completamente engajado na entrega do produto ou } \\
\text { serviço principal da organização. }\end{array}$ \\
\hline Tan e Peng (2003) & $\begin{array}{l}\text { Disponibilidade de recursos de uma empresa necessários } \\
\text { para assegurar sua sobrevivência no longo prazo. A folga } \\
\text { organizacional pode ser utilizada como proteção à organização } \\
\text { de turbulências no ambiente. }\end{array}$ \\
\hline
\end{tabular}

Fonte: Santos (2010: 54).

Observa-se a partir da análise do quadro 1, que o excesso de recursos pode estar relacionado a recursos humanos, físicos e financeiros. Para Santos (2010: 54), "ainda não é unânime a discussão na literatura acerca do papel da folga, ou seja, se a mesma possui influências positivas ou negativas nas organizações".

De acordo com Facó (2009: 67), o "tema folga organizacional pode ser visto sob um prisma que ao mesmo tempo em que promove um incentivo para oportunidades de inovação, também é uma forma de desperdício e gastos que afetam negativamente resultados de desempenho da empresa". A folga é usada para estabilizar as atividades da empresa, absorvendo o excesso de recursos durante períodos de crescimento, possibilitando a manutenção dos seus compromissos durante períodos de crise (George, 2005).

Bromiley (1991) aduz que as atitudes da empresa podem influenciar o desempenho efetivo. Assim, é importante destacar que o excesso ou escassez de folga pode impactar no retorno ou desempenho de uma organização. George (2005) reforça a ideia, citando Nohria e Gulati (1996), que após estudarem o comportamento dos gestores, concluíram que este influencia significativamente a capacidade de inovação da organização. Alguns destes estudos argumentam que os gestores tendem a ter problemas de agência quando há baixa folga organizacional discricionária. 
Por outro lado, George (2005) destaca que o baixo desempenho é suscetível em organizações com alto nível de folga. Neste caso, a folga pode isolar uma empresa de choques externos, gerando complacência de gestão ou otimismo irracional.

Destaca-se que "empresas com grandes reservas de recursos poderiam ser menos impelidas a tomar iniciativas através da experimentação, que pode diminuir o desempenho porque as novas oportunidades empresariais não são exploradas" (George, 2005: 6). O autor adverte que se os gestores percebem que seus níveis absolutos de folga discricionária excedem em muito os dos concorrentes, eles tendem a ser mais otimistas sobre cursos de ação e podem, inadvertidamente, programar ações estratégicas que diminuam o desempenho.

A despeito das divisões da folga organizacional propostas na literatura, George (2005) apresenta um novo elemento na divisão, a folga transitória. Define-a como o excesso de recursos disponíveis após o cumprimento das demandas de recursos para as operações. Esta distinção é teoricamente importante por duas razões. Primeiro, a folga transitória separa a disponibilidade de recursos a partir da demanda de recursos colocada em um sistema. Ao fazer isso, enfatiza os padrões temporais de geração de recursos e perfis de implantação, como as metas e necessidades da organização evoluir num ambiente competitivo (George, 2005).

Em segundo lugar, podem se identificar os efeitos de desempenho de disponibilidade de recursos e a demanda de recursos usando folga passageira. Ou seja, empresas que enfrentam altas exigências, mas com poucos recursos, como muitas empresas orientadas para o crescimento, podem estabelecer estratégias materialmente diferentes de empresas com maior disponibilidade de recursos.

No entendimento de Sender (2004: 35), "a folga exerce basicamente dois papéis em relação a este ambiente em constante evolução: proteção das atividades-chave e flexibilidade de adaptação". Na próxima seção abordam-se as influências que a folga organizacional exerce na gestão das empresas e em seus agentes.

\section{Influências da folga organizacional}

A folga organizacional pode exercer influências positivas ou negativas nas organizações, segundo a literatura. Segundo Sender (2004), o principal estudo sobre fatores de influência na folga organizacional das empresas foi o de Sharfman, Wolf, Chase e Tansik (1988), que relaciona os diversos fatores ao nível de folga 
organizacional. Os fatores apresentados pelos autores como antecedentes foram agrupados em três níveis: estrutura da indústria, características organizacionais e grupos de interesse.

Destaca-se o uso do termo 'antecedentes', para referenciar os fatores que "podem influenciar a existência, a composição e o nível de folga organizacional" (Sender, 2004; 09). O quadro 2 descreve as categorias de antecedentes e os respectivos autores referenciados que abordaram o assunto, segundo pesquisa de Sender (2004).

\section{Quadro 2 \\ Antecedentes da folga organizacional}

\begin{tabular}{|c|c|c|}
\hline Categorias & Descrição dos Antecedentes & Autores \\
\hline \multirow[t]{7}{*}{$\begin{array}{l}\text { Estrutura da } \\
\text { indústria }\end{array}$} & Velocidade e magnitude da mudança & $\begin{array}{l}\text { Sharfman, Wolf, Chase } \\
\text { e Tansik (1988); Marino } \\
\text { e Lange (1983) }\end{array}$ \\
\hline & $\begin{array}{l}\text { Disponibilidade de recursos no mercado } \\
\text { (generosidade) }\end{array}$ & $\begin{array}{l}\text { Sharfman, Wolf, Chase } \\
\text { e Tansik (1988) }\end{array}$ \\
\hline & Natureza básica do output (produto ou serviço) & $\begin{array}{l}\text { Sharfman, Wolf, Chase } \\
\text { e Tansik (1988) }\end{array}$ \\
\hline & Estágio da indústria no ciclo de vida & $\begin{array}{l}\text { Sharfman, Wolf, Chase } \\
\text { e Tansik (1988) }\end{array}$ \\
\hline & $\begin{array}{l}\text { Organizações altamente afetadas pelo seu ambiente } \\
\text { externo, mas que têm pouco controle sobre ele }\end{array}$ & Cheng e Kesner (1997) \\
\hline & Pressões competitivas & $\begin{array}{l}\text { Singh (1986); Marino e } \\
\text { Lange (1983) }\end{array}$ \\
\hline & Mudanças na regulamentação & Marino e Lange (1983) \\
\hline \multirow{5}{*}{$\begin{array}{l}\text { Características } \\
\text { organizacionais }\end{array}$} & Tamanho & \multirow{5}{*}{$\begin{array}{l}\text { Sharfman, Wolf, Chase } \\
\text { e Tansik (1988) }\end{array}$} \\
\hline & Desempenho & \\
\hline & Idade & \\
\hline & Tecnologia & \\
\hline & Estabilidade interna & \\
\hline \multirow{2}{*}{$\begin{array}{l}\text { Grupos de } \\
\text { interesse }\end{array}$} & Comportamento político & \multirow{2}{*}{$\begin{array}{l}\text { Sharfman, Wolf, Chase } \\
\text { e Tansik (1988) }\end{array}$} \\
\hline & Ameaças e oportunidades percebidas & \\
\hline
\end{tabular}

Fonte: Sender (2004: 11)

Para Sharfman, Wolf, Chase e Tansik (1988), a estrutura da indústria está relacionada à natureza de produção da indústria e à fase do ciclo de vida do setor no qual a maioria das empresas do setor se encontra. As características organizacio- 
nais compreendem as características internas da organização, estando ou não sob seu controle (Sender, 2004). Os grupos de interesse correspondem aos valores e crenças da coalizão dominante a cada decisão. Segundo Sender (2004: 24), "cada um destes antecedentes propostos influencia então o nível de determinado tipo de folga organizacional de cada empresa".

Em linha com as influências descritas, no quadro 3 apresentam-se as influências positivas e negativas relatadas na literatura. Note-se que são várias as influências da folga organizacional, com base na revisão de literatura realizada por Neck (2001), conforme citado por Santos (2010).

\section{Quadro 3}

\section{Influências positivas e negativas da folga organizacional}

\begin{tabular}{|c|c|}
\hline \multicolumn{2}{|c|}{ Influências positivas da folga organizacional } \\
\hline Influências & Autores \\
\hline Influencia o ajuste entre estrutura e estratégia & Litschert e Bonham (1978) \\
\hline $\begin{array}{l}\text { Influencia a capacidade de uma empresa para se adaptar } \\
\text { ao seu ambiente }\end{array}$ & $\begin{array}{l}\text { Bourgeois (1981); Hedberg (1981); } \\
\text { Miller, Lant, Milliken e Korn (1996) }\end{array}$ \\
\hline Facilita a inovação & $\begin{array}{l}\text { Cyert e March (1963); Singh (1986); } \\
\text { Damanpour (1987; 1991); Nohria } \\
\text { Gulati (1997) }\end{array}$ \\
\hline Reduz conflitos de meta & Cyert e March (1963) \\
\hline Promove o comportamento político & $\begin{array}{l}\text { Astley (1978); Bourgeois e Singh } \\
\text { (1983) }\end{array}$ \\
\hline Facilita o comportamento criativo estratégico & $\begin{array}{l}\text { Bourgeois (1981); McGrath } \quad \text { e } \\
\text { MacMillan (2000) }\end{array}$ \\
\hline Tampão entre a organização e seu ambiente & $\begin{array}{l}\text { March e Simon (1958); Cyert e March } \\
\text { (1963); Hedberg, Nystrom e Starbuck } \\
\text { (1976); Bourgeois (1981) }\end{array}$ \\
\hline Incentiva a experimentação & $\begin{array}{l}\text { Thompson (1967); Hambrick e Snow } \\
\text { (1977); Bourgeois (1981) }\end{array}$ \\
\hline Amplia a capacidade da organização & Miles (1982); Chakravarthy (1986) \\
\hline $\begin{array}{l}\text { Flexibilidade para cenários futuros ou mudanças } \\
\text { estratégicas; gera futuras opções }\end{array}$ & $\begin{array}{l}\text { March e Simon (1958); Chakravarthy } \\
\text { (1986); Sharfman, Wolf, Chase e } \\
\text { Tansik (1988); Evans (1991); Greenley } \\
\text { e Oktemgil (1998) }\end{array}$ \\
\hline Absorve as flutuações ambientais & $\begin{array}{l}\text { March e Simon (1958); Meyer (1982); } \\
\text { Singh (1986); Sharfman, Wolf, Chase e } \\
\text { Tansik (1988) }\end{array}$ \\
\hline
\end{tabular}




\begin{tabular}{|c|c|}
\hline Salvaguarda a organização de risco negativo & $\begin{array}{l}\text { Miller, Lant, Milliken e Kom (1996); } \\
\text { Singh (1986) }\end{array}$ \\
\hline Incentiva aumento de risco & Moses (1992); Singh (1986) \\
\hline Impede o declínio organizacional & Hambrick e D’Aveni (1988) \\
\hline $\begin{array}{l}\text { Permite que uma empresa renuncie ganhos de curto prazo } \\
\text { em favor de resultados de longo prazo }\end{array}$ & $\begin{array}{l}\text { Bouegeois (1981); Sharfman, Wolf, } \\
\text { Chase e Tansik (1988) }\end{array}$ \\
\hline Aumenta o acesso à informação & Sharfman e Dean (1997) \\
\hline Apóia a exploração das oportunidades & Bourgeois (1981) \\
\hline Fornece incentivos para expansão & Penrose (1995) \\
\hline \multicolumn{2}{|c|}{ Influências negativas da folga organizacional } \\
\hline Influências & Autores \\
\hline Complacência organizacional & $\begin{array}{l}\text { Starbuck, Greve e Hedberg (1978); } \\
\text { Whetton (1980); Tushman e Romanelli } \\
\text { (1985) }\end{array}$ \\
\hline $\begin{array}{l}\text { Gera ineficiência organizacional e não otimiza o } \\
\text { comportamento }\end{array}$ & Bourgeois (1981); Simon (1957) \\
\hline Incentiva a falta de disciplina & Clayton, Gambill e Hamed (1999) \\
\hline Diminui os incentivos para inovar & Leibenstein (1969); Jensen (1986) \\
\hline Promove decisões de investimento não calculadas & $\begin{array}{l}\text { Whetton (1980); Donaldson e Lorsch } \\
\text { (1983) }\end{array}$ \\
\hline As empresas tornam-se vulneráveis a aquisições & Davis e Stout (1992) \\
\hline Gastos descuidados e desperdícios de recursos & McGrath e MacMillan (2000) \\
\hline
\end{tabular}

Fonte: Neck (2001: 33-34), Santos (2010: 56)

No presente estudo não se tem a pretensão de aprofundar a teoria sobre todos os fatores que influenciam a folga organizacional, por não ser este o objetivo do estudo. Serão abordados de forma sucinta aqueles relacionados à análise dos dados, em especial, os fatores relacionados às características organizacionais, como idade e complexidade da organização.

Para George (2005), um provável fator de influência do desempenho é o tempo de atividade da empresa, embora não mencionado nos fatores apresentados por Neck (2001) no quadro 3. Na visão de George (2005), empresas jovens se comportam de maneira diferente do que as empresas a mais tempo estabelecidas. Neste caso, para o autor, a folga também é dependente do tempo, e os níveis de idade e folga são suscetíveis de estarem relacionados de forma positiva. Citando estudos de Levinthal e March (1994), George (2005) destaca que empresas mais velhas possuem uma tendência de melhor desempenho financeiro do que empresas mais jovens, pois estas últimas possuem menos recursos para arriscar. 
Segundo Sharfman, Wolf, Chase e Tansik (1988), as empresas mais velhas têm a oportunidade de experimentar vários tipos de recursos e selecionar aqueles que melhor atendem suas necessidades. George (2005) argumenta que estas empresas possuem necessidades mais previsíveis, e com isso podem melhorar o seu desempenho por meio da utilização de folgas organizacionais.

Para compreender a influência da complexidade da organização, é preciso analisar o ambiente de competição das organizações. As características do ambiente competitivo em que as empresas estão imersas é fator importante para a compreensão da análise dos resultados (Facó, 2009). George (2005) menciona que as organizações precisam adaptar suas estratégias de acordo com o ambiente competitivo. Neste caso, a complexidade da organização influencia as estratégias. A complexidade está relacionada ao mercado de atuação, considerando a concorrência e a alta concentração de mercado que alguns destes concorrentes podem ter.

O grau de complexidade de uma organização é medido pelo índice de concentração denominado Herfindahl-Hirschman. Segundo Rocha (2010: 3), este índice parte do princípio que as medidas de concentração "devem tomar como base as parcelas de mercado de cada firma, além de considerar concentração uma função da desigualdade das parcelas de mercado e do número de firmas".

E por último, ressaltam-se os indicadores de desempenho financeiro que Bourgeois (1981) utilizou para calcular a folga organizacional. Destacam-se os lucros retidos, dividendos, despesas gerais e administrativas, capital de giro, percentual das vendas, dívida em capital, avaliação de crédito, juros de empréstimo de curto prazo em relação à taxa básica de juros, relação preço/lucro. $\mathrm{O}$ autor sugere a combinação de todas ou algumas destas medidas em uma equação linear ou a criação de um índice composto, que seria mais adequado do que usar uma medida de folga isolada.

Concluída a revisão dos fundamentos teóricos do estudo, a próxima seção traz de forma sucinta a trajetória metodológica utilizada por George (2005), seguida nesta pesquisa. 


\section{Apresentação do estudo de George (2005)}

George (2005) publicou no Academy of Management Journal um artigo que pretendia distinguir as várias formas de articular a folga organizacional com o desempenho financeiro das empresas americanas estudadas. De acordo com o autor, a relevância deste estudo está em verificar empresas de capital fechado, já que os estudos anteriores por ele apontados se destinavam a analisar essa relação em empresas de capital aberto.

A amostra da referida pesquisa foi constituída por empresas de estrutura diversificada, englobando 43 subsetores. Foram utilizadas empresas dos subsetores de carne, embalagem de produtos, têxteis, papel e embalagens, madeira, metal, computadores e equipamentos, produtos farmacêuticos, eletrônicos, instrumentação e telecomunicações. Os dados foram extraídos da base de dados Dun Bradstreet e complementados com dados do Diretório de Atividades das empresas de capital fechado. O período de análise correspondeu a quatro anos (1994-1997), pois, segundo o autor, a folga pode ser acumulada e implementada ao longo do tempo. Portanto, a amostra foi composta de 900 empresas.

Para o cálculo da folga organizacional foram utilizados indicadores de desempenho financeiro, como feito em outros estudos (Singh, 1986; Bromiley, 1991; Deephouse e Wiseman, 2000). De acordo com George (2005), o uso de indicadores financeiros é justificado com argumentos que sustentam que é possível, a partir deste tipo de dados, verificar o comportamento do ser humano. Logo, a folga organizacional foi calculada para cada um dos quatro anos de análise.

No estudo de George (2005) foram utilizadas as variáveis descritas no quadro 4.

Quadro 4

Variáveis utilizadas no estudo base

\begin{tabular}{c|c}
\hline Variável & Fórmula \\
\hline Tamanho da empresa & $R=\log$ (valor das vendas) \\
\hline $\begin{array}{c}\text { Rentabilidade da } \\
\text { empresa }\end{array}$ & Número de empresas competindo em público \\
\hline $\begin{array}{c}\text { Número de } \\
\text { concorrentes }\end{array}$ & Número médio de empracional \\
\hline $\begin{array}{c}\text { Tamanho dos } \\
\text { concorrentes }\end{array}$ & Lucro Operacional \\
\hline
\end{tabular}




\begin{tabular}{c|c}
\hline $\begin{array}{c}\text { Complexidade da } \\
\text { indústria }\end{array}$ & $C=$ Índice de Herfindahl (soma dos quadrados das cotas de mercado) \\
\hline Idade da empresa & Anos desde a constituiçãô da empresa \\
\hline Gestão familiar & Variável dummy $(1=$ empresa familiar $; 0=$ empresa não familiar $)$ \\
\hline Alta folga & $B F=\left(\frac{\text { Passico Circulante }+ \text { Passivo no Circulante }}{\text { Patrimônio Líquido }}\right)$ \\
\hline $\begin{array}{c}\text { Baixa folga } \\
\text { Disponibilidade de } \\
\text { recursos }\end{array}$ & $D R=($ Patrimônio Líquido + Dívida $)-($ Ativo Fixo + Ativo não Circulante $)$ \\
\hline $\begin{array}{c}\text { Demanda de recursos } \\
\text { Desempenho } \\
\text { financeiro }\end{array}$ & $D=$ Disponibilidades + Estoques - Contas a Pagar $)$ \\
\hline Número de plantas & DF $=\frac{\text { Lucro Líquido }}{\text { Patrimônio Líquido }}$ \\
\hline
\end{tabular}

Fonte: Adaptado de George (2005)

George (2005) estabeleceu seis hipóteses de pesquisa em seu estudo, elencadas conforme segue:

$\mathrm{H}_{1 \mathrm{a}}$ : Em empresas privadas, o desempenho financeiro aumentará e, em seguida, decrescerá, com o aumento do critério de alta folga.

$\mathrm{H}_{1 \mathrm{~b}}$ : Em empresas privadas, o desempenho financeiro aumentará e, em seguida, decrescerá com o aumento do critério de baixa folga.

$\mathrm{H}_{2 \mathrm{a}}$ : Em empresas de capital fechado, a disponibilidade de recursos será relacionada com o desempenho financeiro. Especificamente o desempenho financeiro irá diminuir ao passo que aumentará a disponibilidade de recursos.

$\mathrm{H}_{2 \mathrm{~b}}$ : Em empresas de capital fechado, a demanda de recursos será relacionada com o desempenho financeiro. Especificamente o desempenho financeiro irá aumentar ou diminuir ao passo que aumentará a disponibilidade de recursos.

$\mathrm{H}_{3}$ : Em empresas de capital fechado, o impacto da folga no desempenho será mais positivo em empresas mais antigas do que em empresas mais jovens.

$\mathrm{H}_{4}$ : Em empresas de capital fechado, o impacto da folga no desempenho será mais negativo em empresas de alta complexidade do que em empresas de baixa complexidade. 
Para confirmar ou rejeitar essas hipóteses, George (2005) utilizou o método de análise de dados em painel, especificamente o modelo de efeitos fixos. O autor optou por essa forma de análise, sob a alegação de ser esta a que melhor se adequa para análises de séries transversais e longitudinais simultaneamente.

\section{Método e procedimentos da pesquisa}

Este estudo foi realizado por meio de pesquisa documental e abordagem quantitativa. Do objetivo da pesquisa, que de acordo com Raupp e Beuren (2001), tem a pretensão de esclarecer aspectos comuns a determinadas populações. No caso desta pesquisa, busca verificar se existe relação entre a folga organizacional e o desempenho financeiro das empresas analisadas.

Quanto aos procedimentos, o estudo foi realizado a partir de pesquisa documental. Segundo Gil (1999), estes estudos baseiam-se em materiais que ainda não receberam tratamento analítico. No estudo em questão, foram utilizadas as demonstrações contábeis divulgadas no site da BM\&FBovespa pelas empresas analisadas.

No que diz respeito à abordagem utilizada, a pesquisa é quantitativa. Conforme Raupp e Beuren (2001: 92), "a abordagem quantitativa caracteriza-se pelo emprego de instrumentos estatísticos, tanto na coleta quanto no tratamento dos dados". Neste estudo, foi utilizado o método dos mínimos quadrados generalizados e viáveis.

Ao contrário do estudo replicado de George (2005), que pesquisou empresas de capital fechado dos Estados Unidos, a amostra deste estudo compreendeu as empresas brasileiras de capital aberto listadas na BM\&FBovespa, devido a disponibilidade apenas dos dados destas empresas. Excluíram-se desta listagem, o setor Financeiro e Outros, já que as empresas que os compõem apresentam características próprias, que podem enviesar e comprometer os resultados da pesquisa. As empresas de capital aberto foram escolhidas devido ao fato de disponibilizarem as demonstrações contábeis no site da BM\&FBovespa.

O período de análise compreendeu cinco anos (2006 a 2010). Esse período foi escolhido em função da convergência das empresas brasileiras às normas internacionais de contabilidade. Essa convergência ocorreu a partir do ano de 2008, logo, o período compreende dois anos antes da adoção, o próprio ano de adoção e dois anos após. 
As variáveis de análise desta pesquisa foram extraídas do estudo do George (2005) e estão descritas no quadro 5.

\section{Quadro 5 \\ Variáveis utilizadas no estudo}

\begin{tabular}{c|c}
\hline Variável & Fórmula \\
\hline Tamanho da empresa & $R O A=\frac{\text { Lucro Operacional }}{\text { Activo Total }- \text { Lucro Operacional }}$ \\
\hline $\begin{array}{c}\text { Rentabilidade da } \\
\text { empresa }\end{array}$ & Anos desde a constituição da empresa \\
\hline Idade da empresa & $A F=$ Nível de reservas de caixa \\
\hline Alta folga & $B F=\left(\frac{\text { Passico Circulante }+ \text { Passivo no Circulante }}{\text { Patrimônio Líquido }}\right)_{x} 100$ \\
\hline Baixa folga & $D=$ Disponibilidades + Estoques - Contas a Pagar $)$ \\
\hline $\begin{array}{c}\text { Disponibilidade de } \\
\text { recursos }\end{array}$ & $D R=($ Patrimônio Líquido + Dívida $)-($ Ativo Fixo + Ativo não Circulante $)$ \\
\hline Demanda de recursos & DF $=\frac{\text { Lucro Líquido }}{\text { Patrimônio Líquido }}$ \\
\hline $\begin{array}{c}\text { Desempenho } \\
\text { financeiro }\end{array}$ & Variável numérica (única planta $=0)$ \\
\hline \begin{tabular}{c} 
Número de plantas \\
\hline
\end{tabular}
\end{tabular}

Fonte: Adaptado de George (2005)

Quatro variáveis do estudo base foram desconsideradas neste estudo, são elas: número de concorrentes, tamanho dos concorrentes, complexidade da indústria e gestão familiar. Estas variáveis não foram utilizadas devido a indisponibilidade dos dados.

Com base na pesquisa de George (2005) foram estabelecidas as hipóteses da pesquisa:

$\mathrm{H}_{1 \mathrm{a}}$ : Em empresas de capital aberto, o desempenho financeiro aumentará e, em seguida, decrescerá, com o aumento do critério de alta folga.

$\mathrm{H}_{1 \mathrm{~b}}$ : Em empresas de capital aberto, o desempenho financeiro aumentará e, em seguida, decrescerá com o aumento do critério de baixa folga.

$\mathrm{H}_{2 \mathrm{a}}$ : Em empresas de capital aberto, a disponibilidade de recursos será relacionada com o desempenho financeiro. Especificamente, o desempenho financeiro irá diminuir ao passo que aumentará a disponibilidade de recursos. 
$\mathrm{H}_{2 \mathrm{~b}}$ : Em empresas de capital aberto, a demanda de recursos será relacionada com o desempenho financeiro. Especificamente, o desempenho financeiro irá aumentar ao passo que aumentará a disponibilidade de recursos.

$\mathrm{H}_{3}$ : Em empresas de capital aberto, o impacto da folga no desempenho será mais positivo em empresas mais antigas do que em empresas mais jovens.

Essas hipóteses foram retiradas do estudo de George (2005). Apenas a $\mathrm{H}_{4}$ do estudo original não foi incluída no presente estudo, visto que esta compara a folga com a complexidade da indústria, variável que não foi contemplada nesta pesquisa devido a indisponibilidade de dados enquanto usuário externo das demonstrações contábeis.

Para proceder à análise dos dados, seguindo a metodologia adotada no estudo de George (2005), nesta pesquisa foi utilizada a análise de dados em painel. Conforme explicam Silva e Cruz Júnior (2004), a expressão dados em painel faz menção ao conjunto de dados nos quais se têm dados sobre o mesmo indivíduo ao longo de vários períodos de tempo, ou seja, ao mesmo procede-se uma análise longitudinal e transversal simultaneamente.

Os dados foram coletados na Economática, além de consultas nas demonstrações contábeis disponibilizadas pela BM\&FBovespa em seu respectivo endereço eletrônico, cujos dados foram armazenados em planilhas eletrônicas. Por sua vez, os procedimentos de análise dos dados foram realizados com o auxílio dos softwares SPSS 13.0 e Eviews 7.

\section{Análise dos resultados}

Este estudo teve como objetivo identificar a relação de diferentes formas de folga organizacional com o desempenho das empresas listadas na BM\&FBovespa, levando em consideração fatores antecedentes destacados por Sharfman, Wolf, Chase e Tansik (1988). Nesse sentido realizou-se a análise dos dados e apresentam-se os resultados nesta seção.

O quadro 6 apresenta o coeficiente de correlação de Pearson entre as variáveis, bem como a estatística descritiva das variáveis, com o intuito de caracterizar os dados utilizados no estudo. Foi usada correlação de Pearson em função de se es- 
tar utilizando dados financeiros, sendo, desta forma, a correlação mais adequada (Fávero, 2009).

\section{Quadro 6}

\section{Correlações e estatística descritiva}

\begin{tabular}{|c|c|c|c|c|c|c|c|c|c|}
\hline 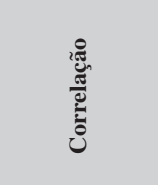 & 尽 & 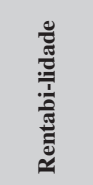 & $\begin{array}{l}\frac{\pi}{0} \\
\frac{0}{0} \\
\frac{\pi}{2} \\
\frac{\pi}{4}\end{array}$ & 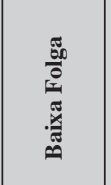 & 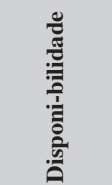 & 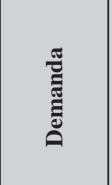 & 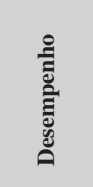 & 흘 & 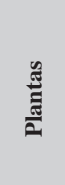 \\
\hline Tamanho & 1 & & & & & & & & \\
\hline Rentabilidade & $-0.066^{*}$ & 1 & & & & & & & \\
\hline Alta Folga & $0.257 * *$ & -0.009 & 1 & & & & & & \\
\hline Baixa Folga & $-0.063^{*}$ & -0.003 & -0.008 & 1 & & & & & \\
\hline $\begin{array}{l}\text { Disponibili- } \\
\text { dade }\end{array}$ & $-0.083 * *$ & 0.001 & $-0.468 * *$ & 0.026 & 1 & & & & \\
\hline Demanda & $-0.281 * *$ & 0.008 & $-0.670 * *$ & -0.018 & $0.509 * *$ & 1 & & & \\
\hline Desempenho & $-0.070 * *$ & 0.006 & -0.005 & $-0.133 * *$ & 0.001 & 0.000 & 1 & & \\
\hline Idade & $0.152 * *$ & -0.031 & -0.040 & $-0.058^{*}$ & $-0.075^{* *}$ & -0.021 & -0.011 & 1 & \\
\hline Plantas & $0.249 * *$ & -0.044 & $0.139 * *$ & 0.049 & -0.008 & $-0.104 * *$ & $-0.063^{*}$ & $-0.097 * *$ & 1 \\
\hline \multicolumn{10}{|l|}{$\begin{array}{l}\text { Estatística } \\
\text { Descritiva }\end{array}$} \\
\hline Mínimo & 0.000 & -32.210 & -9.000 & -9.140 .89 & $-8.3 E+07$ & $-1.1 \mathrm{E}+08$ & -51.420 & 0.000 & 0.000 \\
\hline Máximo & 7.920 & 549.360 & 24.814 .26 & 86.910 .17 & 27.492 .35 & 7.019 .031 & 80.860 & 138 & 1.000 \\
\hline Média & 5.198 & 0.487 & 450.908 .3 & 300.336 & -124.96 & -1.830 .29 & 0.189 & 36.590 & 0.765 \\
\hline Desvio-padrão & 1.878 & 14.907 & 1.295 .133 & 2.869 .667 & 4.762 .732 & 5.835 .207 & 2.888 & 29.847 & 0.424 \\
\hline
\end{tabular}

* Correlação significativa ao nível de 0.1 .

** Correlação significativa ao nível de 0.05.

Fonte: Dados da pesquisa

Conforme evidenciado no quadro 6 , nenhuma das variáveis possui coeficiente de correlação forte, porém algumas variáveis apresentaram correlação significante. Destaque para a correlação entre demanda e alta folga, que apresentou o maior coeficiente, -0.670 , ou seja, quanto mais se aumenta a demanda, menor é o critério de alta folga e vice-versa. A demanda compõe-se das disponibilidades (reservas de caixa e dinheiro depositado em Bancos) acrescidas dos estoques e subtraídas as contas a pagar. O critério de alta folga corresponde ao nível de reservas de caixa da empresa. 
O coeficiente observado na análise parece razoável com a prática empresarial, que quando ocorre um aumento súbito na demanda, haverá um decréscimo na folga de reservas de caixa da empresa, pelo menos no curto prazo. No longo prazo pode ocorrer uma harmonização entre as entradas e saídas de recursos financeiros, mas no curto prazo tende a aumentar o volume de produção/estoque e o financiamento das vendas e a consequente queda no nível de folga das reservas de caixa.

Ainda cabe ressaltar o coeficiente de correlação apresentado pelas variáveis demanda e disponibilidades, sendo 0.509. Nesse caso, conforme se aumenta a demanda, ter-se-á aumentada a disponibilidade. A disponibilidade foi calculada subtraindose o montante do Patrimônio Líquido + Dívida da empresa do seu montante de Ativo Fixo + Ativo Não Circulante. Portanto, o Ativo Circulante (disponibilidade) tende a aumentar com o aumento da demanda, seja com a entrada de caixa ou aumento de duplicatas a receber.

Com o intuito de fazer uma análise inicial acerca da relação entre o desempenho financeiro e os critérios de alta folga e de baixa folga elaboraram-se as Figuras 1 e 2. Optou-se por utilizar os critérios de folga organizacional em relação ao desempenho financeiro, visto que esta modalidade de folga é a mais difundida na literatura e a mais objetiva para mensurar. Dessa forma, foi possível obter uma análise prévia das hipóteses $\mathrm{H}_{1 \mathrm{a}}$ e $\mathrm{H}_{1 \mathrm{~b}}$. A figura 1 apresenta o comportamento da Alta Folga em relação ao desempenho financeiro das organizações.

Figura 1

Comportamento da alta folga em relação ao desempenho

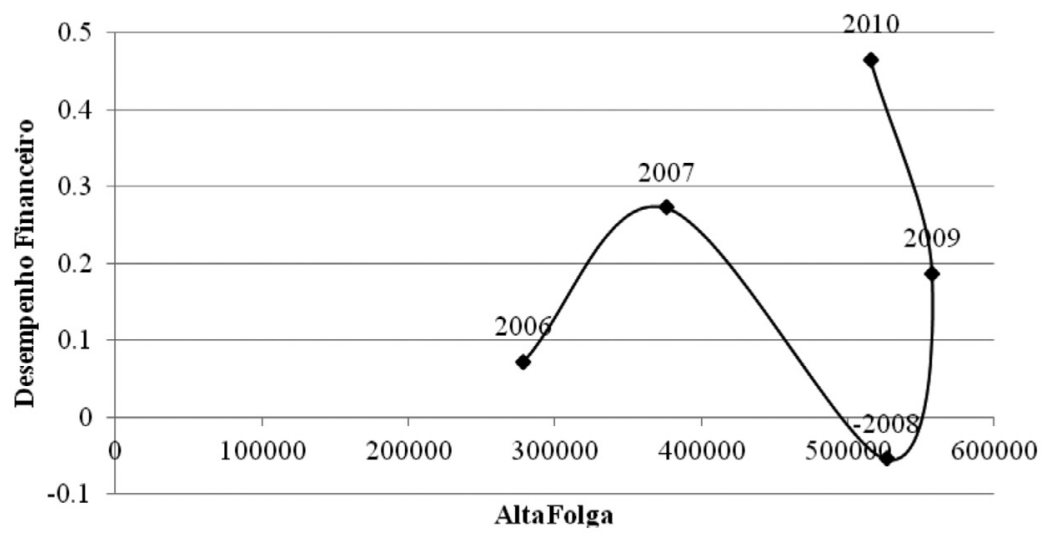

Fonte: Dados da pesquisa 
Conforme evidenciado na figura 1, a alta folga se apresenta crescente até o ano de 2009 , porém em 2010, observa-se um pequeno decréscimo nesse critério. É possível que cenários econômicos de crise, em especial a crise subprime anunciada em 2008, que em seguida se alastrou para a Europa e depois para outros continentes, tenham contribuído para esse resultado. O critério de alta folga é justamente o nível de reservas de caixa, que pode ter sido reduzido devido a esse fenômeno.

O desempenho financeiro (Lucro Líquido dividido pelo Patrimônio Líquido) mostrou uma acentuada queda no ano de 2008, período de início de crise, que pode ter influenciado no lucro líquido das empresas analisadas, diminuindo assim o seu desempenho financeiro. Porém não é possível garantir que essa seja a única causa dessa queda na variável desempenho financeiro, visto que o cenário econômico pode ser influenciado por outras variáveis.

Embora o desempenho financeiro tenha caído substancialmente em 2008, o reflexo ocorrido na alta folga (nível de reservas de caixa) só foi percebido nos anos seguintes. Tal pode decorrer da existência de reservas de caixa em anos anteriores e que só foram corroídas pela queda do desempenho financeiro de 2008 nos anos seguintes.

Pela análise realizada não se pode depreender que as alterações no desempenho financeiro tenham ocorrido por causa das mudanças em critérios contábeis, a partir da convergência às Normas Internacionais de Contabilidade pelas empresas brasileiras em 2008. Alterações no desempenho das empresas, conforme já comentado, podem ser decorrentes da crise financeira mundial que se manifestou em 2008, inicialmente nos Estados Unidos.

Ressalta-se que estas duas variáveis foram relacionadas com vistas a analisar as variáveis relativas a hipótese $\mathrm{H}_{1 \mathrm{~b}}$. Nesse sentido, a figura 2 apresenta o comportamento da baixa folga em relação ao desempenho financeiro das organizações. 
Figura 2

Comportamento da baixa folga em relação ao desempenho

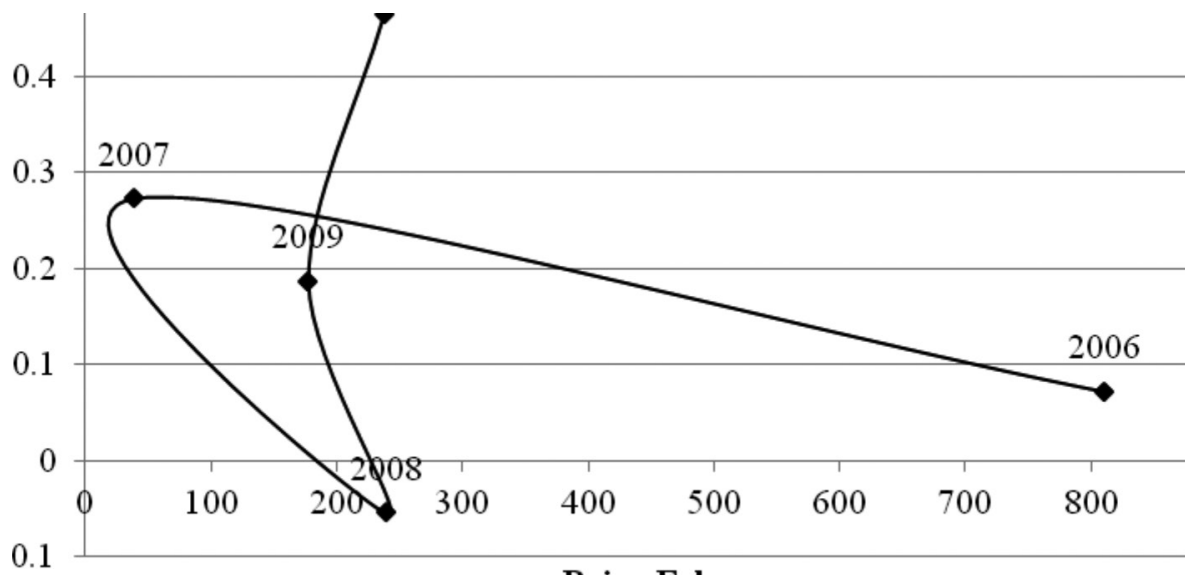

Baixa Folga

Fonte: Dados da pesquisa

Conforme a figura 2, é possível verificar que o critério de baixa folga decresceu de 2006 para 2007, cresceu em 2008, decresceu em 2009 e novamente cresceu em 2010. Esse comportamento da baixa folga sugere que essa variável é mais suscetível do que a alta folga, pois trata da relação entre as dívidas da empresa e seu patrimônio líquido.

A baixa folga foi calculada dividindo-se o Passivo Circulante + Passivo Não Circulante pelo Patrimônio Líquido. Portanto, a baixa folga em 2008 pode ser explicada pela involução do desempenho financeiro (Lucro Líquido dividido pelo Patrimônio Líquido) daquele ano, que apresentou uma acentuada queda em relação aos anos anteriores. Denota-se que a baixa folga varia de acordo com o desempenho financeiro, que se reflete no Patrimônio Líquido das empresas com maiores ou menores níveis de lucros.

O quadro 7 apresenta os resultados da análise de painel realizada com as variáveis em relação ao desempenho financeiro para testar o comportamento da folga. São apresentados seis diferentes modelos, iniciando com o básico e encerrando com o modelo completo. 


\section{Quadro 7}

\section{Estimativa da folga}

\begin{tabular}{|c|c|c|c|c|c|c|}
\hline \multirow[t]{2}{*}{ Variáveis } & \multicolumn{2}{|c|}{ Modelo 1} & \multicolumn{2}{|c|}{ Modelo 2} & \multicolumn{2}{|c|}{ Modelo 3} \\
\hline & C & E.P. & C & E.P. & $\mathrm{C}$ & E.P. \\
\hline Tamanho & -0.03002 & 0.03043 & -0.01399 & 0.03048 & -0.01332 & 0.03061 \\
\hline Rentabilidade & -0.00130 & 0.00527 & -0.00115 & 0.00514 & -0.00121 & 0.00515 \\
\hline Idade & -0.00075 & 0.00265 & -0.23962 & 0.18565 & -0.23560 & 0.18585 \\
\hline Plantas & -0.31066 & 0.18872 & -0.00217 & 0.002634 & -0.00300 & 0.00291 \\
\hline Alta Folga & & & $1.6 \mathrm{E}-08$ & $1.17 \mathrm{E}-07$ & $-1.2 \mathrm{E}-07$ & $2.60 \mathrm{E}-07$ \\
\hline$(\text { Alta Folga) })^{2}$ & & & $3.6 \mathrm{E}-16$ & 7.48E-15 & $1.9 \mathrm{E}-14$ & $4.20 \mathrm{E}-14$ \\
\hline Baixa Folga & & & $-0.0006^{* *}$ & 7.37E-05 & $-0.0006 * *$ & $7.39 \mathrm{E}-05$ \\
\hline$(\text { Baixa Folga })^{2}$ & & & $7.3 \mathrm{E}-09^{* *}$ & $9.85 \mathrm{E}-10$ & $7.4 \mathrm{E}-09^{* *}$ & $9.86 \mathrm{E}-10$ \\
\hline Disponibilidade & & & $9.0 \mathrm{E}-09$ & $1.90 \mathrm{E}-08$ & $1.1 \mathrm{E}-08$ & $1.94 \mathrm{E}-08$ \\
\hline$(\text { Disponibilidade })^{2}$ & & & $2.1 \mathrm{E}-17$ & $3.10 \mathrm{E}-16$ & $3.2 \mathrm{E}-18$ & $3.20 \mathrm{E}-16$ \\
\hline Demanda & & & $-9.4 \mathrm{E}-09$ & $1.66 \mathrm{E}-08$ & $-9.5 \mathrm{E}-09$ & $1.67 \mathrm{E}-08$ \\
\hline$(\text { Demanda })^{2}$ & & & $-2.6 \mathrm{E}-17$ & $2.28 \mathrm{E}-16$ & $-5.8 \mathrm{E}-17$ & $2.34 \mathrm{E}-16$ \\
\hline Alta folga X Idade & & & & & $3.2 \mathrm{E}-09$ & 4.74E-09 \\
\hline (Alta Folga) $^{2}$ X Idade & & & & & $-3.4 \mathrm{E}-16$ & $6.54 \mathrm{E}-16$ \\
\hline Constante & $0.56250 * *$ & 0.19829 & $0.60733 * *$ & 0.332 .19614 & $0.64197 * *$ & 0.20277 \\
\hline Log-likelihood & \multicolumn{2}{|c|}{-3369.462} & \multicolumn{2}{|c|}{-3332.376} & \multicolumn{2}{|c|}{-3332.142} \\
\hline $\mathrm{R}^{2}$ & \multicolumn{2}{|c|}{0.007364} & \multicolumn{2}{|c|}{0.060050} & \multicolumn{2}{|c|}{0.060374} \\
\hline
\end{tabular}

\begin{tabular}{|c|c|c|c|c|c|c|}
\hline \multirow[t]{2}{*}{ Variáveis } & \multicolumn{2}{|c|}{ Modelo 4} & \multicolumn{2}{|c|}{ Modelo 5} & \multicolumn{2}{|c|}{ Modelo 6} \\
\hline & C & E.P. & C & E. $P$. & C & E.P. \\
\hline Tamanho & -0.0193 & 0.0302 & 0.0306 & -0.4944 & 0.6935 & 0.201922 \\
\hline Rentabilidade & -0.0013 & 0.0051 & 0.0052 & -0.2299 & -0.0192 & 0.030485 \\
\hline Idade & -0.2339 & 0.1840 & 0.1861 & -1.2482 & -0.0013 & 0.005110 \\
\hline Plantas & -0.0040 & 0.0026 & 0.0028 & -0.9824 & -0.2303 & 0.184645 \\
\hline Alta Folga & $-6.3 \mathrm{E}-09$ & $1.2 \mathrm{E}-07$ & $1.3 \mathrm{E}-07$ & -0.0992 & -0.0044 & 0.002951 \\
\hline$(\text { Alta Folga })^{2}$ & $1.3 \mathrm{E}-15$ & 7.4E-15 & 7.7E-15 & 0.0740 & $-9.1 \mathrm{E}-08$ & $2.61 \mathrm{E}-07$ \\
\hline Baixa Folga & $-0.0009 * *$ & 8.9E-05 & 7.4E-05** & -8.5624 & $1.0 \mathrm{E}-14 * *$ & $4.26 \mathrm{E}-14$ \\
\hline$(\text { Baixa Folga })^{2}$ & $1.1 \mathrm{E}-08 * *$ & 1.2E-09 & $9.9 \mathrm{E}-10 * *$ & 7.4692 & $-0.0009 * *$ & $9.00 \mathrm{E}-05$ \\
\hline Disponibilidade & 9.5E-09 & $1.9 \mathrm{E}-08$ & 3.7E-08 & 0.6765 & $1.1 \mathrm{E}-08$ & $1.21 \mathrm{E}-09$ \\
\hline (Disponibilidade) $^{2}$ & $\begin{array}{l}4, . . \text { manda }^{2} \\
\text { X IdadeX } \\
\text { dade4E-17 }\end{array}$ & $3.1 \mathrm{E}-16$ & 7.0E-16 & -0.2139 & 3.2E-08 & $3.70 \mathrm{E}-08$ \\
\hline Demanda & $-1.0 \mathrm{E}-08$ & 1.6E-08 & $1.8 \mathrm{E}-08$ & -0.1867 & $-1.2 \mathrm{E}-16$ & $7.18 \mathrm{E}-16$ \\
\hline$(\text { Demanda })^{2}$ & $-3.0 \mathrm{E}-17$ & $2.3 \mathrm{E}-16$ & 1.2E-15 & $0, . .19 .2592$ & $-7.2 \mathrm{E}-09$ & $1.82 \mathrm{E}-08$ \\
\hline Alta folga X Idade & & & & & $5.7 \mathrm{E}-16$ & $1.25 \mathrm{E}-15$ \\
\hline $\begin{array}{l}(\text { Alta Folga) })^{2} X \\
\text { Idade }\end{array}$ & & & & & $1.8 \mathrm{E}-09$ & 5.12E-09 \\
\hline Baixa Folga X Idade & $1.4 \mathrm{E}-05^{*} *$ & 2.9E-06 & & & $-1.6 \mathrm{E}-16^{*}$ & 6.64E-16 \\
\hline
\end{tabular}




\begin{tabular}{c|c|l|c|c|c|c}
\hline $\begin{array}{c}\text { (Baixa Folga) }^{2} \mathrm{X} \\
\text { Idade }\end{array}$ & $-4.1 \mathrm{E}-10^{*}$ & $2, . .4 \mathrm{E}-10$ & & & $1.4 \mathrm{E}-05^{*}$ & $2.93 \mathrm{E}-06$ \\
\hline $\begin{array}{c}\text { Disponibilidade X } \\
\text { Idade }\end{array}$ & & & $8.1 \mathrm{E}-10$ & -0.1344 & $-4.1 \mathrm{E}-10$ & $2.45 \mathrm{E}-10$ \\
\hline $\begin{array}{c}\text { (Disponibilidade) } \\
\text { X Idade }\end{array}$ & & & $8.3 \mathrm{E}-18$ & 0.5753 & $-2.4 \mathrm{E}-10$ & $8.30 \mathrm{E}-10$ \\
\hline Demanda X Idade & & & $6.3 \mathrm{E}-10$ & -0.0 .7370 & $5.5 \mathrm{E}-18$ & $8.23 \mathrm{E}-18$ \\
\hline (Demanda) $^{2}$ X Idade & & & $1.9 \mathrm{E}-17$ & -0.4661 & $-6.0 \mathrm{E}-12$ & $6.82 \mathrm{E}-10$ \\
\hline Constante & $0.6778 * *$ & 0.1949 & $0.6217 * *$ & 0.1978 & $0.6935 * *$ & 0.2019 \\
\hline Log-likelihood & -3319.440 & -3332.000 & -3319.073 \\
\hline $\mathrm{R}^{2}$ & 0.077763 & \multicolumn{2}{c|}{$0,332.060571$} & \multicolumn{2}{c}{0.078261} \\
\hline
\end{tabular}

C - coeficiente; E. P. - erro padronizado

* Coeficiente significativo ao nível de 0.1 .

** Coeficiente significativo ao nível de 0.05.

Fonte: Dados da pesquisa

No quadro 7 verifica-se que os coeficientes de explicação $\left(R^{2}\right)$ dos modelos não são altos, porém eles aumentaram do modelo básico para o modelo completo. Este último apresentou um $\mathrm{R}^{2}$ de $7.83 \%$, ou seja, o modelo completo é capaz de explicar praticamente $8 \%$ da folga organizacional das empresas de capital aberto brasileiras. Uma vez mais, justifica-se a escolha da variável dependente, desempenho financeiro, pela objetividade de mensuração da mesma. O comportamento de todas as outras variáveis explica o desempenho financeiro das empresas analisadas e, dessa forma, tanto o critério de alta folga quanto o critério de baixa folga influenciam no desempenho financeiro das empresas analisadas.

Este baixo coeficiente de explicação não condiz com os resultados encontrados no estudo de George (2005), visto que em sua pesquisa o autor encontrou coeficientes de explicação que variavam entre $30 \%$ e $56 \%$. É possível que os resultados não coadunem pelo fato de a presente pesquisa analisar empresas estabelecidas em país distinto e em período diferente do estudo base, e que estudou empresas de capital fechado dos Estados Unidos.

Seguindo o procedimento adotado no estudo base, nos modelos 3, 4, 5 e 6 foram incluídas variáveis ao quadrado. George (2005) justifica essa inclusão ponderando que estes termos fornecem explicação mais completa, de forma a evitar interpretações equivocadas. Para justificar a multiplicação de algumas variáveis pela idade da empresa, o argumento utilizado por George (2005) é de que um efeito moderador foi adicionado aos modelos. 
De acordo com os resultados expostos no quadro 7, o padrão dos modelos não foi alterado, pois desde o modelo 2 até o 6 , apenas as variáveis relacionadas ao critério de baixa folga apresentaram significância, evidenciando que das variáveis analisadas, a que melhor explica o desempenho financeiro é a relação entre as dívidas e o patrimônio das empresas. O modelo 1 não se enquadra nessa análise, pois não possui uma variável diretamente relacionada à baixa folga, reiterando os resultados apresentados anteriormente. Portanto, pode-se afirmar que a significância dos modelos não foi alterada de forma contundente.

George (2005) encontrou resultado semelhante em sua pesquisa. Os resultados também não apresentaram alteração de significância, com exceção da variável de baixa folga, que se apresentou significativa até o modelo 3 , e que passou a não ter significância no modelo 4 e assim seguindo até o modelo completo. Ressalta-se que o critério de baixa folga apresentou comportamento semelhante, tanto nas empresas de capital aberto quanto nas empresas de capital fechado, depreendendo-se que a relação entre as dívidas e o patrimônio líquido possui comportamento parecido nas duas modalidades de empresa.

Para testar as hipóteses $\mathrm{H}_{1_{\mathrm{a}}}$ e $\mathrm{H}_{1}$ utilizaram-se as equações descritas pelos mode$\operatorname{los} 3$ e 4 , respectivamente. A hipótese $\mathrm{H}_{1_{\mathrm{a}}}$, de que nas empresas de capital aberto, o desempenho financeiro aumentaria e, em seguida, decresceria, com o aumento do critério de alta folga, não pode ser aceita, visto que as variáveis relacionadas ao critério de alta folga não se apresentaram significativas. A alta folga é caracterizada pelo nível de reservas de caixa das empresas, assim, dizer que elas não foram significativas nos modelos é o mesmo que afirmar que essas reservas não contribuem para o desempenho financeiro das empresas.

Por sua vez, a hipótese $\mathrm{H}_{1 \mathrm{~b}}$, de que nas empresas de capital aberto, o desempenho financeiro aumentaria e, em seguida, decresceria com o aumento do critério de baixa folga, pode ser aceita, já que as variáveis Baixa Folga (Baixa Folga) ${ }^{2}$, Baixa Folga X Idade e (Baixa Folga) ${ }^{2} \mathrm{X}$ Idade se mostraram significativas no modelo testado e, conforme já mencionado anteriormente, apresenta-se significativa a relação entre as dívidas e o patrimônio líquido da empresa para a explicação da variável desempenho financeiro.

$\mathrm{O}$ modelo 5 serviu como base para testar as hipóteses $\mathrm{H}_{2 \mathrm{a}}$ e $\mathrm{H}_{2 \mathrm{~b}}$. A hipótese $\mathrm{H}_{2 \mathrm{a}}$, afirma que em empresas de capital aberto, a disponibilidade de recursos está relacionada com o desempenho financeiro, mas esta não pode ser confirmada, visto 
que as variáveis de disponibilidade não se mostraram significantes. A variável disponibilidades foi mensurada como a diferença entra a soma do patrimônio líquido com as dívidas e a soma dos ativos fixos com o ativo não circulante, mas essa relação entre passivo e ativo circulante não é capaz de explicar o desempenho financeiro das empresas, visto que esta não se apresentou significante.

Também não foi possível aceitar a hipótese $\mathrm{H}_{2 \mathrm{~b}}$, de que em empresas de capital aberto, a demanda de recursos está relacionada com o desempenho financeiro. Novamente, as variáveis relacionadas à demanda não apresentaram significância. A variável demanada foi calculada somando-se as disponibilidades e os estoques, e subtraindo-se as contas a pagar, e também não se mostrou significante no quesito explicação da variável dependente desempenho financeiro. Parece razoável que se o critério de alta folga não foi significante, a demanda também não seja, pois ambos dizem respeito a valores mais imediatos das empresas.

Por fim, para testar a hipótese $\mathrm{H}_{3}$, utilizou-se o modelo completo (6). Essa hipótese afirma que em empresas de capital aberto, o impacto da folga no desempenho é mais positivo em empresas mais antigas do que em empresas mais jovens. Entretanto, não foi possível aceitá-la, pois a variável idade não se apresentou significante. Em outras palavras, o tempo de atuação das empresas no mercado não é suficiente para explicar o seu desempenho financeiro.

De forma geral, depreende-se que apenas o critério de baixa folga é capaz de explicar parcialmente o desempenho financeiro das empresas de capital aberto brasileiras, ao passo que as demais variáveis analisadas não apresentam essa capacidade. Logo, o critério de baixa folga é o que mais afeta o desempenho financeiro das empresas dentre as variáveis analisadas.

\section{Conclusões}

Esta pesquisa objetivou identificar a relação de diferentes formas de folga organizacional com o desempenho financeiro das empresas listadas na BM\&FBovespa, levando em consideração fatores antecedentes destacados por Sharfman, Wolf, Chase e Tansik. (1988). A coleta de dados das empresas compreendeu o período de 2006 a 2010. Para a análise destes, inicialmente calculou-se a matriz de correlação das variáveis e apresentou-se a estatística descritiva das variáveis. Nesse sentido merece destaque o comportamento da demanda em relação ao critério de alta fol- 
ga, que apresentou o maior coeficiente de correlação. Parece razoável concluir que, quando ocorre um aumento súbito na demanda financeira haverá um decréscimo na folga de reservas de caixa da empresa no curto prazo.

Elaboraram-se também dois gráficos para analisar o comportamento dos critérios de alta e baixa folga em relação ao desempenho financeiro das organizações. $\mathrm{Na}$ relação entre o critério de alta folga e o desempenho financeiro, foi possível constatar que até o ano de 2009 o critério de alta folga cresceu, ao passo que em 2010 verificou-se um pequeno decréscimo. Não é possível afirmar que essa mudança de comportamento tenha ocorrido em função de alterações no cenário contábil, decorrentes da convergência às Normas Internacionais de Contabilidade, pois nesse período ocorreu também a crise financeira mundial.

Por sua vez, na relação entre o critério de baixa folga e desempenho financeiro, analisado na segunda figura, evidenciou-se que o comportamento do critério de folga não é linear, tendo em vista suas evoluções e involuções. Portanto, é possível estabelecer que a baixa folga varia de acordo com o desempenho financeiro, que se reflete no Patrimônio Líquido das empresas com maiores ou menores níveis de lucros.

Em seguida, efetuou-se a análise de dados em painel, utilizando o modelo de efeitos fixos, com o intuito de testar as hipóteses estabelecidas na pesquisa. Das cinco hipóteses testadas, apenas uma delas pode ser aceita, $\mathrm{a} \mathrm{H}_{1 \mathrm{~b}}$. Em outras palavras, $\mathrm{O}$ aumento do critério de baixa folga apresenta relação significativa com o aumento, no curto prazo, e o decréscimo, no longo prazo, do desempenho financeiro.

De modo geral, conclui-se que a folga organizacional foi constituída de forma diferente nas empresas de capital fechado pesquisadas por George (2005) e as de capital aberto objeto deste estudo, visto que os modelos utilizados naquele estudo não foram altamente explicativos nesta pesquisa. Todavia, obteve-se relação significante entre o desempenho financeiro e o critério de baixa folga. Assim, ainda que de modo preliminar, é possível concluir que o aumento da baixa folga implica em aumento do desempenho financeiro, mas no longo prazo esse desempenho apresenta uma tendência de decréscimo.

Diferenças nos resultados de ambas as pesquisas podem decorrer de diferentes critérios contábeis adotados nos Estados Unidos e Brasil. Nos Estados Unidos a convergência contábil às International Financial Reporting Standards (IFRS) ainda está em fase de estudos, enquanto no Brasil é obrigatória a partir de 2008. Portanto, 
George (2005) considerou um período anterior a convergência contábil, enquanto que nesta pesquisa se considerou um período de mudanças nas normas contábeis. Outro aspecto a ressaltar é a época de realização da pesquisa, uma vez que o contexto econômico dos dois momentos diferentes pode ter influenciado os resultados. Amplia-se assim o campo de investigação para buscar possíveis explicações sobre as divergências entre ambas as pesquisas. Recomenda-se reaplicar o estudo em empresas brasileiras de capital fechado, para verificar se o comportamento da folga organizacional é o mesmo nas empresas brasileiras e americanas. Outra sugestão é mudar as variáveis pesquisadas, com o intuito de melhorar o poder explicativo dos modelos, permitindo assim, que a folga organizacional seja explicada de forma mais precisa. Recomenda-se ainda reaplicar a pesquisa em empresas americanas em período posterior a convergência contábil e comparar os resultados com os achados desta pesquisa.

\section{Referências}

Astley, W.G. (1978). Sources of power in organizational life. Unpublished Doctoral Dissertation. University of Washington.

Barnard, C. (1938). The functions of the executive. New York: Wiley.

Bourgeois, L. J. (1981). On the measurement of organizational slack. The Academy of Management Review 6 (1): 29-39.

\& J. V. Singh (1983). Organizational slack and political behavior among top management teams. Academy of Management Proceedings: 43-47.

Bromiley, P. (1991). Testing a causal model or corporate risk taking and performance. The Academy of Management Journal 34 (1): 37-59.

Chakravarthy, B. S. (1986). Measuring strategic performance. Strategic Management Journal 7: 437-458.

Cheng, J. L. C. \& I. F. Kesner (1997). Organizational slack and responseto environmental shifts: the impact of resource allocation patterns. Journal of Management 23 (1): 1-18. 
Clayton, J., B. Gambill \& D. Hamed (1999). The curse of too much capital: building new businesses in large corporations. The McKinsey Quarterly 4: 48-59.

Cyert, R.M. \& J. G. March (1963). A behavioral theory of the firm. Englewood Cliffs, NJ: Prentice Hall.

Damanpour, F. (1987). The adoption of technological, administrative and ancillary innovations: impact of organizational factors. Journal of Management 13 (4): 675-688.

(1991). Organizational innovation: a meta-analysis of effects of determinants and moderators. Academy of Management Journal 34 (3): 555-590.

Davis, G. F. \& S. K. Stout (1992). Organization theory of market for corporate control: a dynamic analysis of the characteristics of large takeover targets 1980-1990. Administrative Science Quaterly 37 (4): 605-633.

Deephouse, D. \& R. Wiseman (2000). Comparing alternative explanations for accounting risk-return relations. Journal of Economic Behavior \& Organization 42: 463-482.

Dimick, D.E. \& V. Murray (1978). Correlates of substantive policy decisions in organizations: the case of human resource management. The Academy of Management Journal 21 (4): 611-623.

Donaldson, G. \& J. W. Lorsch (1983). Decision making at the top. New York: Basic Books.

Evans, D. S. (1991). Strategic flexibility for high-technology maneurvers: A conceptual framework. Journal of Managerial Studies 28: 67-89.

Facó, J. F. B. (2009). Capacidade de inovação organizacional: uma análise aplicada à indústria de transformação paulista. 215 f. Tese (Doutorado em Administração) - Universidade de São Paulo, São Paulo.

Fávero, L. P. (2009). Análise de dados: modelagem multivariada para tomada de decisões. Rio de Janeiro: Elsevier, Campus. 
George, G. (2005). Slack resources and the performance of privately held firms. The Academy of Management Journal 48 (4): 661-676.

Gil, A. C. (1999). Métodos e técnicas de pesquisa social. 5. ed. São Paulo: Atlas.

Greenley, G. E. \& M. Oktemgil (1998). A comparison of slack resources in high and low performing British companies. Journal of Management Studies 35 (3): 377-398.

Hambrick, D. C., \& R.A. D’Aveni (1988). Large corporate failuries as downward spiral. Administrative Science Quaterly 33: 1-23.

Hambrick, D.C., C. C. \& Snow (1977). A contextual model of strategic decision making in organizations. Academy of Management Proceedings: 109-112.

Hedberg, B. L. T. (1981). How organizations learn and unlearn. In: P.C. Nystrom \& W. H. Starbuck (eds.). The handbook of organizational design. New York: Oxford University Press 1: 3-27.

Hedberg, B. L. T., P. C. Nystrom \& W. H. Starbuck (1976). Camping on seesaws: prescriptions for a self-designing organization. Administrative Science Quarterly 21: 41-65.

Jensen, M. C. (1986). Agency costs of free cash flow, corporate finance, and takeovers. American Economic Review 76: 323-329.

Kren, L. (2003). Effects of uncertainty, participation, and control system monitoring on the propensity to create budget slack and actual budget slack created. Advances in Management Accounting 11: 143-167.

Lawson, M. B. (2001). In praise of slack: time is of the essence. The Academy of Management Executive 15 (3): 125-136.

Leibenstein, H. (1969). Organizational or frictional equilibria, X-efficiency, and the rate of innovation. Quarterly Journal of Economics 83: 600-623.

Levinthal, D. \& J. March (1981). A model of adaptative organizational search. Journal of Economics Behavior and Organization 2 (4): 307-333. 
Lima, A. F. (2008). Estudo da relação causal entre os níveis organizacionais de folga, o risco e o desempenho financeiro de empresas manufatureiras. $252 \mathrm{f}$. Tese (Doutorado em Administração de Empresas) - Universidade Presbiteriana Mackenzie, São Paulo.

Litschert, R. J. \& T. W. Bonham (1978). A conceptual model of strategy formation. Academy of Management Review: 211-219.

March, J. G. \& H.Simon (1958). Organizations. New York: Wiley.

Marino, K.E. \& D. R. Lange (1983). Measuring Organizational Slack: A note on the convergence and divergence of alternative operational definitions. Journal of Management 9 (1): 81-92.

McGrath, R.G. \& I. MacMillan (2000). The entrepreneurial mindset: strategies for continuously creating opportunity in an age of uncertainty. Boston: Harvard Business School Press.

Meyer, A. D. (1982). Adapting to organizational jolts. Administrative Science Quarterly 27 (4): 515-537.

Miles, R. E. (1982). Coffin nails and corporate strategies. Englewood Cliffs, NJ: Prentice-Hall.

Miller, D., T. K. Lant, F. J. Milliken \& H. J. Kom (1996). The evolution of strategic simplicity: Exploring two models of organizational adaption. Journal of Management 22 (6): 863-887.

Moses, D. O. (1992). Organizational slack and risk-taking behavior: tests of product pricing strategy. Journal of Organizational Change Management 5 (3): 38-54.

Neck, H. M. (2001). Firm growth following the intial public offering: the impact of organizational slack on the productive opportunity of high technology entrepreneurial firms. $216 \mathrm{f}$. Thesis (Psychology Doctorate)-Department of Business Policy and Strategy, University of Colorado, Colorado. 
Nohria, N. \& R. Gulati (1997). What is the optimum amount of organizational slack? A study of the relationship between slack and innovation in multinational firms. European Management Journal 15 (6): 603-611.

(1996). Is slack good or bad for innovation? Academy of Management Journal 39: 1245-1264.

Penrose, E. (1995). The theory of the growth of the firm. 3rd ed. Oxford: Oxford University Press.

Raupp, F.M. \& I.M. Beuren (2001). Metodologia da pesquisa aplicável às ciências sociais. In: Beuren, I.M. (Org.). Cómo elaborar trabalhos monográficos em contabilidade: teoria e prática. 3rd ed. São Paulo: Atlas.

Rocha, F. (2010). Dinâmica da concentração de mercado na indústria brasileira, 1996-2003. Economia e Sociedade, Campinas 19 (3): 477-498.

Santos, V. (2010). Percepção de justiça na avaliação de desempenho versus folga organizacional dos controllers: um estudo em empresas com sistemas de remuneração por recompensa. 168 f. Dissertação (Mestrado em Ciências Contábeis)-Universidade Regional de Blumenau, Blumenau.

Sender, G. (2004). O papel da folga organizacional nas empresas: um estudo em bancos brasileiros. Dissertação (Mestrado em Administração) - COPPEAD/ UFRJ, Rio de Janeiro.

Sharfiman, M. P. \& J. W. J. Dean, (1997). Flexibility in strategic decision making: informational and ideological perspectives. Journal of Management Studies 34 (2): 191-217.

Sharfman, M.P., G. Wolf, R. B. Chase \& D. A. Tansik (1988). Antecedents of organizational slack. The Academy of Management Review 13 (40): 601-614.

Simon, H. A. (1957). Administrative behavior. New York: Free Press.

Singh, J. (1986). Performance, slack, and risk taking in organizational decision making. Academy of Management Journal 29: 562-585. 
Silva, O.M. \& J. C. Cruz Júnior (2004). Dados em painel: uma análise do modelo estatístico. In M. L. Santos \& W. C.Vieira (orgs.). Métodos quantitativos em economia. Viçosa: UFV.

Starbuck, W. H., A. Greve \& B. L. T. Hedberg (1978). Responding to crisis. Journal of Business Administration 9: 111-137.

Tan, J., \& M. W. Peng (2003). Organizational slack and firm performance during economic transitions: Two studies from an emerging economy. Strategic Management Journal 24: 1249-1263.

Thompson, J. D. (1967). Organization in action. New York: McGraw-Hill, 1967.

Tushman, M.L. \& E. Romanelli (1985). Organizational evolution: a metamorphosis model of convergence and reorientation. In B. M. Staw \& L. L. Cummings (eds.). Research in organizational behavior. Greenwich, CT: JAI Press 7: 171- 222.

Whetton, D. A. (1980). Sources, responses, and the effects of organiational decline. In J. Kimberly \& R.H. Miles (eds.). The organizational life cycle. San Francisco: Jossey-Bass: 342-374.

Wiseman, R. \& P. Bromiley (1996). Towards a model of risk in declining organizations: An empirical examination of risk, performance and decline. Organization Science 7: $524-543$. (A) 
